\title{
A possible nitrogen crisis for Archean life due to reduced nitrogen fixation by lightning
}

Rafael Navarro-González*, Christopher P. McKay† \& Delphine Nna Mvondo*

*Laboratorio de Química de Plasmas y Estudios Planetarios, Instituto de Ciencias

Nucleares, Universidad Nacional Autónoma de México, Circuito Exterior, C.U.,

Apartado Postal 70-543, México D.F. 04510, MEXICO

†Space Science Division, NASA-Ames Research Center, Moffett Field, CA 94035-1000, USA

Nitrogen is an essential element for life and is often the limiting nutrient for terrestrial ecosystems ${ }^{1,2}$. The principal reservoir of nitrogen is molecular nitrogen in the atmosphere. However to be available for organisms nitrogen must be in the form of ammonia or nitrate, forms known as fixed nitrogen. Due to the strength of the triple bond in $\mathrm{N}_{2}$, nitrogen fixation, while thermodynamically favored is kinetically restricted ${ }^{3}$. The development of biological nitrogen fixation must have occurred early in earth history when the biological demand exceeded the main abiotic source: production of nitric oxide by lightning in the early atmosphere composed of carbon dioxide and dinitrogen. Here we report an experimental study of the nitrogen fixation rate over the evolution of the pre-oxygenic atmosphere: from predominantly carbon dioxide to predominantly dinitrogen. Our results indicate that the production of nitric oxide drastically decreased from

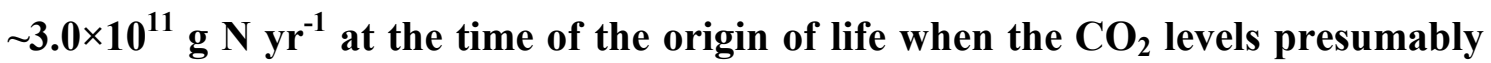




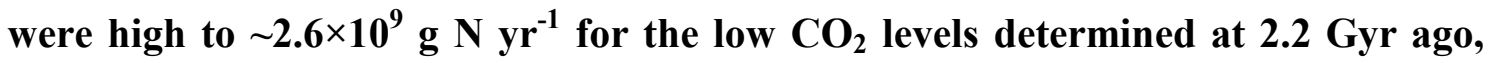
just before the start of the rise of oxygen in the atmosphere. This reduction in NO production may have caused an ecological crisis that triggered the development of biological nitrogen fixation before a new increase in abiotic nitrogen fixation resulted from either the rise of atmospheric $\mathrm{CH}_{4}$ or $\mathrm{O}_{2}$ from biological activity.

Because biological nitrogen fixation is energetically expensive and does not occur if adequate supplies of fixed nitrogen are available, it has been generally thought that the development of metabolic pathways to fix nitrogen arose only in response to a crisis in the supply of fixed nitrogen on the early Earth. Cloud ${ }^{4}$ and others ${ }^{5,6,7}$ have suggested that this crisis occurred soon after the origin of life as the prebiotic source of organic material was depleted by the emerging life forms. In this scenario, the abiotic sources of fixed nitrogen were unable to sustain even simple microbial ecosystems. In contrast Mancinelli and McKay $^{8}$, noting that many modern microbially-dominated ecosystems are satisfied with abiotic inflows of fixed nitrogen and do not express nitrogen fixation, posited that nitrogen fixation arose late only when biological demand increased with the development of higher plants and exceeded the abiotic supply.

In both of these scenarios the key question is the rate of abiotic nitrogen fixation by lightning. Yung and McElroy ${ }^{9}$ computed the lightning fixation rate on the early Earth for atmospheres containing $\mathrm{N}_{2}$ and $\mathrm{H}_{2} \mathrm{O}$ suggesting a source of $\sim 10^{12} \mathrm{~g} \mathrm{~N} \mathrm{yr}^{-1}$. Kasting and Walker ${ }^{10}$ and Kasting ${ }^{11}$ considered more realistic atmospheres composed primarily of $\mathrm{CO}_{2}$ and determined a production rate from thermodynamic equilibrium models of $\geq 10^{12} \mathrm{~g} \mathrm{~N} \mathrm{yr}^{-1}$, and noted that recycling by atmospheric photochemistry would return $25 \%$ of this to $\mathrm{N}_{2}$, reducing the net source of fixed nitrogen ${ }^{10}$. The only previous 
experimental determination of fixation in $\mathrm{CO}_{2}$ dominated atmospheres is the work of Levine et $\mathrm{al}^{12}$ who measured $\mathrm{NO}_{\mathrm{x}}$ production in a simulated Venus atmosphere of $95.9 \%$ $\mathrm{CO}_{2}, 3.97 \% \mathrm{~N}_{2}$ and traces of $\mathrm{SO}_{2}, \mathrm{Ar}$, and $\mathrm{CO}$.

The thermodynamic equilibrium models cited above 9,10 and used in all other previous studies of nitrogen fixation by lightning on the early Earth $^{8,13}$ are only approximate because they compute the fixation rate by assuming that the chemical reactions proceed rapidly at high temperatures and then are quenched or "freeze out" at some specified temperature between 2000 and $3000 \mathrm{~K}$. The equilibrium concentration at this freeze out temperature determines the final production. To accurately determine the nitrogen fixation rate by lightning in $\mathrm{CO}_{2}$ atmospheres, we have experimentally determined the production of NO by simulated lightning as described in the methods.

Figure 1 shows the variation of the NO production rate with the carbon dioxide mixing ratio, $\chi \mathrm{CO}_{2}$. For comparison the results obtained for the simulation of the present Venusian (Ref. 12) and Terrestrial (Ref. 14) lightning are presented. Our results indicate that the energy yield of production of nitric oxide increases from $\sim 1.9 \times 10^{15}$ molecule $\mathrm{J}^{-1}$ at $\chi \mathrm{CO}_{2} \sim 0.98$ to $\sim 1.3 \times 10^{16}$ molecule $\mathrm{J}^{-1}$ at $\chi \mathrm{CO}_{2} \sim 0.80$. This yield is insensitive down to about $\chi \mathrm{CO}_{2} \sim 0.50$. At lower mixing ratios the $\mathrm{NO}$ yield drastically decreases to $\sim 2.4 \times 10^{14}$ molecule $\mathrm{J}^{-1}$ at $\chi \mathrm{CO}_{2} \sim 0.20$ and then slowly diminishes to $\sim 1.1 \times 10^{14}$ molecule $\mathrm{J}^{-1}$ at $\chi \mathrm{CO}_{2} \sim 0.025$. Any further decrease in the atmospheric $\mathrm{CO}_{2}$ content has little impact at this point since the water vapor present in the atmosphere contributes oxygen atoms for the production of $\mathrm{NO}$, stabilizing it at about $7.0 \times 10^{13}$ 
molecule $\mathrm{J}^{-1}$. For experiments conducted at $\chi \mathrm{CO}_{2} \sim 0.80$, it was found that the NO production yield is not pressure dependent. The efficient production of $\mathrm{NO}$ in $\mathrm{CO}_{2}$ dominated mixtures can be explained by the thermal dissociation of carbon dioxide leading to the formation of atomic oxygen according to reaction 1:

$\mathrm{CO}_{2} \rightarrow \mathrm{O}+\mathrm{CO}$

Most of the $\mathrm{O}$ produced in reaction 1 combines to form $\mathrm{O}_{2}$. However at temperatures above $1500^{\circ} \mathrm{C}$, a small fraction of the $\mathrm{O}$ results in the formation of $\mathrm{NO}$ via the following reaction chain:

$\mathrm{O}+\mathrm{N}_{2} \rightarrow \mathrm{NO}+\mathrm{N}$

$\mathrm{N}+\mathrm{CO}_{2} \rightarrow \mathrm{NO}+\mathrm{CO}$

In competition are the following reactions which destroy NO:

$\mathrm{NO}+\mathrm{N} \rightarrow \mathrm{N}_{2}+\mathrm{O}$

$\mathrm{NO}+\mathrm{O} \rightarrow \mathrm{N}+\mathrm{O}_{2}$

At low $\mathrm{CO}_{2}$ mixing ratios, water vapor from the atmosphere contributes to the formation of atomic oxygen via the following set of reactions:

$\mathrm{H}_{2} \mathrm{O} \rightarrow \mathrm{H}+\mathrm{OH}$

$\mathrm{OH}+\mathrm{OH} \rightarrow \mathrm{H}_{2} \mathrm{O}+\mathrm{O}$ 
The drastic reduction in the $\mathrm{NO}$ production in $\mathrm{N}_{2}$ dominated atmospheres $\left(\chi \mathrm{CO}_{2} \leq 0.20\right)$ is attributed to the efficient third-body conversion of atomic nitrogen into dinitrogen ${ }^{15,16}$ (reaction 8), transforming reaction 3 into a negligible channel.

$2 \mathrm{~N}+\mathrm{N}_{2} \rightarrow 2 \mathrm{~N}_{2}$

In contemporaneous lightning where oxygen would be a dominant species, reaction 1 and 5 would be replaced by the following set of equations, respectively:

$\mathrm{O}_{2} \rightarrow \mathrm{O}+\mathrm{O}$

$\mathrm{N}+\mathrm{O}_{2} \rightarrow \mathrm{NO}+\mathrm{O}$

The formation of atomic oxygen in reaction 10 enhances the production of NO via reactions 2 and 10 . The ratio of $\mathrm{NO}$ to $\mathrm{CO}$ in the product gases varies as expected based on this reaction scheme. In our experiments the $\mathrm{CO}$ to $\mathrm{NO}$ ratio is over 200 for $\mathrm{CO}_{2}$ mixing ratios near unity and then drops rapidly to values between $30-60$ for $\mathrm{CO}_{2}$ mixing ratios between 0.8 and 0.2 (figure 2). Below $\mathrm{CO}_{2}$ mixing ratios of 0.2 the $\mathrm{CO}$ to $\mathrm{NO}$ ratio climbs again to high values, reaching 180 for $\chi \mathrm{CO}_{2}=0.025$. The shape of this curve for $\chi \mathrm{CO}_{2}>0.2$ is as expected if the freeze out temperature is constant. However, the increase in $\mathrm{CO} / \mathrm{NO}$ at low $\chi \mathrm{CO}_{2}$ is not predicted by a constant freeze out model. Freezout temperature variations of about $1000 \mathrm{~K}$, and different freeze out temperatures for $\mathrm{NO}$ and $\mathrm{CO}$ would be required to explain this difference. The increasing importance of reaction 8 at low $\chi \mathrm{CO}_{2}$ in our proposed chemical scheme can satisfactorily account for this increase in the $\mathrm{CO} / \mathrm{NO}$ ratio. 
It is unclear how the lightning flashing rate would have varied on the early Earth; however, assuming that it remained constant at $1 \times 10^{18} \mathrm{~J} \mathrm{yr}^{-1}$ over time ${ }^{17}$, our results (Figure 1) imply that the annual production rate of NO was of the order of $\sim 3.0 \times 10^{11} \mathrm{~g}$ $\mathrm{N}$ whenever $\mathrm{CO}_{2}$ was the dominant atmospheric gas. This is likely to have been the case during the Hadean, when chemical evolution and the origin of life probably occurred. However, paleosol measurements ${ }^{18}$ indicate that at $2.2 \mathrm{Gyr}$ ago $\mathrm{CO}_{2}$ levels had dropped to $<0.04$ bar. As seen from Figure 1, this drop in $\mathrm{CO}_{2}$ caused lightning production of NO to rapidly decrease to $\sim 2.6 \times 10^{9} \mathrm{~g} \mathrm{~N} \mathrm{yr}^{-1}$ until large increase in abiotic nitrogen fixation resulting either from the rise of atmospheric oxygen or production of $\mathrm{HCN}$ in a $\mathrm{CH}_{4}$ rich atmosphere ${ }^{19}$. We suggest that a crisis in the supply of fixed nitrogen occurred as a result of this factor of a 100 decrease in NO production prompting the development of biological nitrogen fixation.

Abiotic production might have increased before the rise of $\mathrm{O}_{2}$ due to $\mathrm{HCN}$ formation from $\mathrm{CH}_{4}$ by methanogenic bacteria. Models of the early greenhouse effect suggest that biogenic methane levels increased as the $\mathrm{CO}_{2}$ levels declined and became the dominant greenhouse gas ${ }^{20,21}$ with a mixing ratio of $\sim 10^{-3}$. Photochemical models by Zahnle ${ }^{19}$ suggest that $\mathrm{HCN}$ formation occurs at a significant rate when the $\mathrm{CH}_{4}$ mixing ratio exceeds $10^{-5}$ for a 100 times the present atmospheric levels of $\mathrm{CO}_{2}$ (see Fig. 1). Climate models ${ }^{20}$ suggest that this occurred only when the $\mathrm{CO}_{2}$ mixing ratios fell to below 0.1. Thus the nitrogen crisis would have occurred when the $\mathrm{CO}_{2}$ mixing ratio was $0.1 \geq \chi \mathrm{CO}_{2} \leq 0.2$. The atmospheric $\mathrm{CO}_{2}$ removal rate for the Precambrian is unknown; however, assuming that the $\mathrm{CO}_{2}$ levels dropped linearly from the Hadean to early Proterozoic, when the oldest $\mathrm{CO}_{2}$ paleosol record exist ${ }^{18}$, this crisis could have 
lasted in the order of $10^{8}$ yrs even though it was confined to a narrow window in the atmospheric $\mathrm{CO}_{2}$ concentration. Even if this figure were over estimated by several orders of magnitude, a shortage of reactive nitrogen to the Archean Biosphere of more than $10^{3}$ yrs would have had dramatic ecological consequences.

The key reactions that form $\mathrm{HCN}$ in a $\mathrm{CH}_{4}$-rich atmosphere are:

${ }^{3} \mathrm{CH}_{2}+\mathrm{N} \rightarrow \mathrm{HCN}+\mathrm{H}$
$\mathrm{CH}_{3}+\mathrm{N} \rightarrow \mathrm{HCN}+\mathrm{H}_{2}$

but their rate constants and products have not yet been studied experimentally. In fact, these reactions were considered to be similar to another reaction ${ }^{22}$ :

$\mathrm{CH}+\mathrm{N} \rightarrow \mathrm{HCN}$

The rate of this reaction has been measured and is fast but the products have not yet been identified. Current kinetic databases ${ }^{16}$ suggest that reaction 11 does not produce $\mathrm{HCN}$ but rather $\mathrm{CH}+\mathrm{NH}$ based on bond energy-bond order theory. If $\mathrm{NH}$ radical is produced instead, this could lead to the production of ammonia. Therefore, the question of abiotic nitrogen fixation in $\mathrm{CH}_{4}$-rich atmospheres is unresolved and further work is needed. If no net production of fixed nitrogen took place in $\mathrm{CH}_{4}$-rich atmospheres, then abiotic nitrogen fixation increased only with the rise of atmospheric $\mathrm{O}_{2}$ at about $2.2 \mathrm{Gyr}$ ago. 
There are other indications that nitrogen fixation arose early in the history of life. These include: (i) Evidence of the phylogenetic antiquity of the genes for biological nitrogen fixation ${ }^{23}$; (ii) Nitrogen $15 / 14$ isotopic ratios ${ }^{24}$ consistent with fixation before 3.5 Gyr ago; (iii) The oxygen sensitivity of the nitrogen fixation process ${ }^{1}$ which implies an origin predating the rise of atmospheric oxygen ${ }^{25}$ about 2 Gyr ago; (iv) The presence of heterocysts formed by nitrogen fixing cyanobacteria in fossils ${ }^{26}$ of $1.5-1.3$ Gyr age; and (v) The antiquity of cyanobacteria as indicated by hopanoids found in $2.7 \mathrm{Gyr}$ sediments $^{27}$, by morphological evidence for cyanobacteria at 3.5 Gyr ago showing both microfossils similar to modern cyanobacteria as well as stromatolites ${ }^{28}$, and by possible evidence for cyanobacteria at $3.8 \mathrm{Gyr}$ ago in the carbon isotopes ${ }^{29}$ showing a characteristic enrichment in ${ }^{12} \mathrm{C}$.

Our results suggest that the development of biological nitrogen fixation arose in response to changes in atmospheric composition that resulted in a reduction in the production of abiotically fixed nitrogen. The biochemistry of the nitrogen fixing process, in particular its sensitivity to oxygen, may reflect the timing of nitrogen crisis and illustrates the co-evolution of the metabolic pathways in life and the environment of the early Earth.

\section{Methods}

Lightning in the laboratory was simulated by a plasma generated with a Q-switched NdYAG laser. The temperature of this plasma ${ }^{30}$ has been determined to be about $20,000 \mathrm{~K}$ at $1 \mu$ s after initiation. The laser delivers a beam of $1.06 \mu \mathrm{m}$ photons with an energy of up to $600 \mathrm{~mJ}$ per pulse in 5-7 ns at $10 \mathrm{~Hz}$. A beam with $300 \mathrm{~mJ}$ per pulse was focused 
inside a closed 1-liter Pyrex flask with a plano-convex optical glass lens which is expected to have a focal aberration of $\sim 10 \mu \mathrm{m}$. The power deposited into the system was determined calorimetrically. Our power meter was calibrated with the heating rate produced by passing a known electric current through a resistor. The power deposited was found to depend on the chemical composition of the gas mixture used, varying from $1.5 \mathrm{~W}$ for $100 \% \mathrm{CO}_{2}$ to $1.9 \mathrm{~W}$ for $50 \% \mathrm{CO}_{2}$ in $\mathrm{N}_{2}$ to $2.3 \mathrm{~W}$ for $100 \% \mathrm{~N}_{2}$. The energy dissipated per unit length in this simulated lightning was estimated to be $\sim 10^{4} \mathrm{~J} \mathrm{~m}^{-1}$, in close agreement with that from natural lightning. Most experiments were conducted at 1 bar total pressure. In another series of experiments, the pressure was varied ( 0.2 to 1.0 bar). In some additional experiments water vapor was introduced into the reactors to achieve a $100 \%$ relative humidity. The main nitrogen-containing lightning product was determined to be nitric oxide by infrared and mass spectroscopy. The NO production rate was derived from the slope of a linear fit to the number of molecules $v s$ energy deposited.

1. Postgate, J. Nitrogen fixation (Edward Arnold, Kent, Great Britain, ed. 2, 1987), 73 pp.

2. Rosswall, T. in Some Perspectives of the Major Biogeochemical Cycles (ed. Likens, G.E.) Chapter 2 (Wiley, New York, 1981).

3. Howard, J.B. \& Rees, D.C. Structural basis of biological nitrogen fixation, Chem. Reviews 96, 2965-2982 (1996). 
4. Cloud, P.E. Atmospheric and hydrospheric evolution on the primitive Earth, Science 160, 729-736 (1968).

5. Walker, J.C.G. Evolution of the Atmosphere (MacMillan Co., New York, 1977).

6. Schopf, J. W., Ed. Earth's earliest biosphere: It's origin and evolution (Princeton University Press, Princeton, New Jersey, 1983).

7. Raven, J.A. \& Yin, Z.H. The past, present and future of nitrogenous compounds in the atmosphere, and their interactions with plants, New Phytol. 139, 205-219 (1998).

8. Mancinelli, R.L. \& McKay, C.P. The evolution of nitrogen cycling, Origins Life Evol. Biosph. 18, 311-325 (1988).

9. Yung, Y.L. \& McElroy, M.B. Fixation of nitrogen in the prebiotic atmosphere, Science 203, 1002-1004 (1979).

10. Kasting, J.F. \& Walker, J.C.G. Limits on oxygen concentrations in the prebiological atmosphere and the rate of abiotic fixation of nitrogen, J. Geophys. Res. 86, $1147-$ $1158(1981)$.

11. Kasting, J.F. Bolide impacts and the oxidation state of carbon in the Earth's early atmosphere, Origins Life Evol. Biosph. 20, 199-231 (1990).

12. Levine, J.S. et al. Production of nitric oxide by lightning on Venus, Geophys. Res. Lett. 9, 893-896 (1982). 
13. Chameides, W.L. \& Walker, J.C.G. Rates of fixation by lightning of carbon and nitrogen in possible primitive atmospheres, Origins Life 11, 291-302 (1981).

14. Wang, Y., DeSilva, A.W., Goldenbaum, G.C. \& Dickerson, R.R. Nitric oxide production by simulated lightning: Dependence on current, energy, and pressure, $J$. Geophys. Res. 103, 19149-19159 (1998).

15. Knipovich, O.M., Rubtsova, E.A. \& Nekrasov, L.I. Volume recombination of nitrogen atoms in the afterglow of a condensed discharge, Russ. J. Phys. Chem. 62, 867- 870 (1988).

16. NIST Standard Reference Database 17-2Q98, National Institute of Standards and Technology, Gaithersburg, MD 20899 USA.

17. Chyba, C. \& Sagan, C. Electrical energy sources for organic synthesis on the early Earth, Origins Life Evol. Biosphere 21, 3-17 (1991).

18. Rye, R., Kuo, P.H. \& Holland, H.D. Holland, Atmospheric carbon dioxide concentrations before 2.2 billion years ago, Nature 378, 603-605 (1995).

19. Zahnle, K.J. Photochemistry of methane and the formation of hydrocyanic acid (HCN) in the Earth's early atmosphere, J. Geophys. Res. 91, 2819-2834 (1986).

20. Pavlov, A.A., Kasting, J.K., Brown, L.L., Rages, K.A. \& Freedman, R. Greenhouse warming by $\mathrm{CH}_{4}$ in the atmosphere of early Earth, J. Geophys. Res. 105, 11981$11990(2000)$. 
21. Kasting, J.F. Pavlov, A.A. \& Siefert, J.L. A coupled ecosystem-climate model for predicting the methane concentration in the Archean atmosphere, Origins Life Evol. Biosph. (in press).

22. Yung, Y.L., Allen, M. \& J.P. Pinto. Photochemistry of the atmosphere of Titan, Astrophys. J. Supp. 203, 465-506 (1984).

23. Young, J.P.W. in Biological Nitrogen Fixation (Eds. Stacey, G., Burris, R.H. \& Evans, H.J.) pp. 43-86 (Chapman \& Hall, New York, 1992).

24. Beaumont, V. \& Robert, F. Nitrogen isotope ratios of kerogens in Precambrian cherts: a record of the evolution of atmospheric chemistry?, Precambrian Res. 96, 63-82 (1999).

25. Rye, R. \& Holland, H.D. Paleosols and the evolution of atmospheric oxygen: a critical review, Am. J. Science 298, 621-672 (1998).

26. Golubic, S., Sergeev, V.N. \& Knoll, A.H. Mesoproterozoic Archaeoellipsoides: akinetes of heterocystous cyanobacteria, Lethaia 28, 285-298 (1995).

27. Brocks, J.J., Logan, G.A., Buick, R. \& Summons, R. Archean molecular fossils and the early rise of eukaryotes, Science 285, 1033-1036 (1999).

28. Schopf, J.W. \& Parker, B.M., Early Archean (3.3-billion to 3.5-billion-year-old) microfossils from Warrawoona Group, Australia, Science 237, 70-73 (1987).

29. Schopf, J.W. in Prokaryotic Development (Eds. Brun, Y.V. \& Shimkets, L.J.) pp. 105-129 (American Society of Microbiology, Washington, D.C., 2000). 
30. Jebens, D.S., Lakkaraju, H.S. McKay, C.P. \& Borucki, W.J. Time resolved simulation of lightning by LIP, Time resolved simulation of lightning by LIP, Geophys. Res. Lett. 19, 273-276 (1992).

Acknowledgements.

This work was supported by grants from the National Autonomous University of Mexico, the National Council of Science and Technology of Mexico and the NASA Astrobiology program. The authors acknowledge the assistance of Leonel Calva-Alejo. We are indebted to William Schopf and Andy Knoll for their discussions on the paleontological evidence of nitrogen fixation. We would also like to thank Jim Kasting and Akiva Bar-Nun for their stimulating discussions that greatly improved this work.

Correspondence and requests for materials should be addressed to R. N.-G. (e-mail: Navarro@nuclecu.unam.mx).

Figure 1. Variation of the nitric oxide yield as a function of the $\mathrm{CO}_{2}$ mixing ratio in simulated lightning in primitive atmospheres composed of $\mathrm{CO}_{2}-\mathrm{N}_{2}$ at 1 bar under anhydrous $(\bigcirc)$ and hydrated $(\bullet)$ conditions. All samples were irradiated at $20^{\circ} \mathrm{C}$ from 5 to 30 minutes. Immediately after irradiation, an aliquot $(2 \mathrm{ml})$ was introduced with an automatic gas sampling loop into a gas chromatograph interfaced in parallel with a FTIR-detector and a quadrupole mass spectrometer. Two capillary chromatographic columns were used for the separation of lightning products: PoraPlot $\mathrm{Q}(25 \mathrm{~m} \times 0.32 \mathrm{~mm}$ I.D. $)$ and Alumina $/ \mathrm{KCl}(50 \mathrm{~m} \times 0.32 \mathrm{~mm}$ I.D.). For comparison the results obtained for the simulation of the present Venusian $(\Delta)$ and Terrestrial $(\square)$ lightning are presented. Also shown is the possible production of HCN based on the Zahnle mechanism ${ }^{19}$ for methane mixing ratios (dotted line) needed to offset the 
reduced $\mathrm{CO}_{2}$ and keep surface temperature constant at $288.15 \mathrm{~K}$ (present level) based on Kasting et $a l^{21}$. Time proceeds nonlinearly from left to right.

Figure 2. Ratio of $\mathrm{NO}$ to $\mathrm{CO}$ produced in laser discharge as a function of $\mathrm{CO}_{2}$ concentration $(O)$. Also shown are the predictions (line) of the freeze out models for freeze out temperatures between 2000 and $3000 \mathrm{~K}$, the extreme range of freeze out models. 


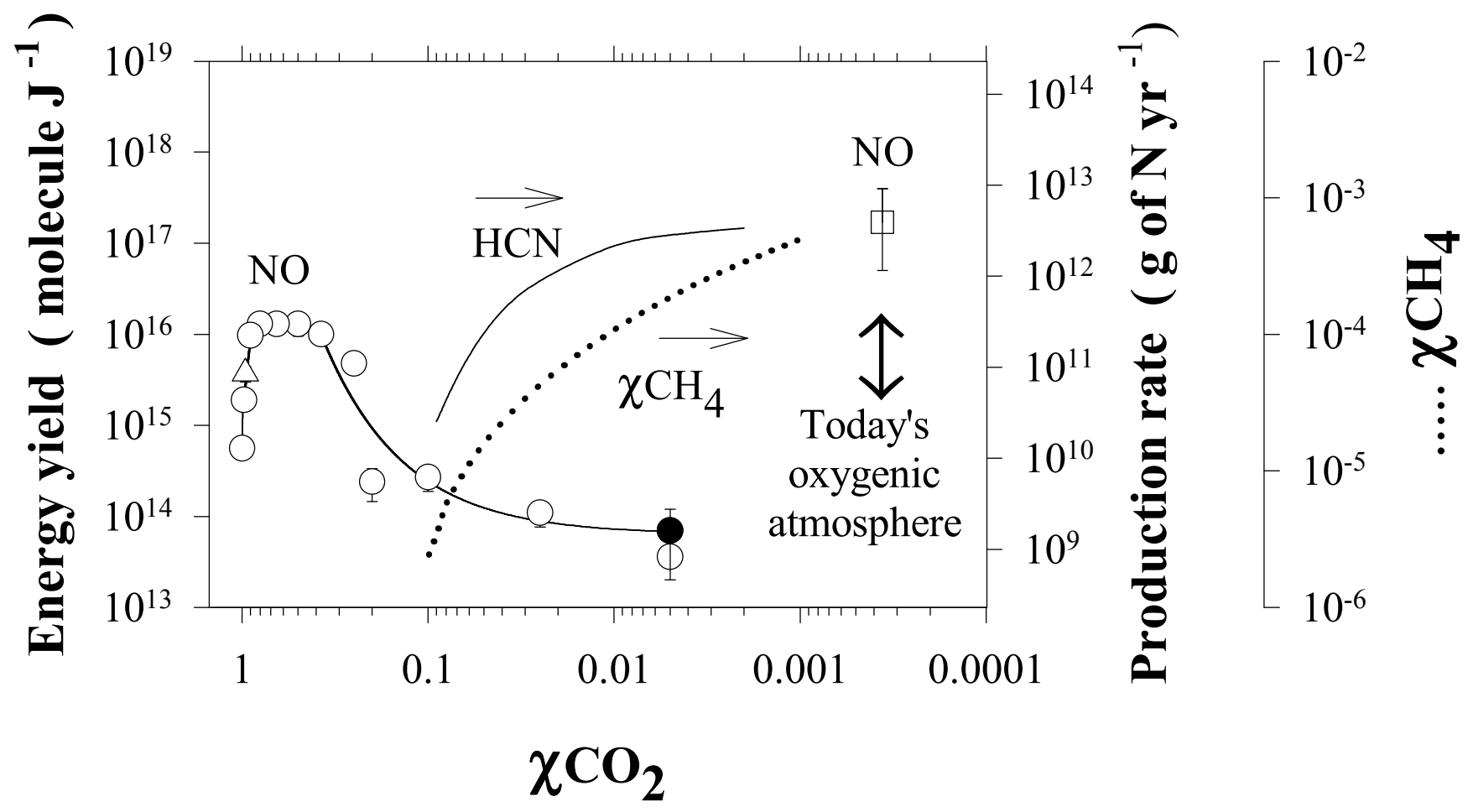

Figure 1

Ms. No. N11260B

Navarro-González et al. 
Final draft post-refereeing - Submission to Nature

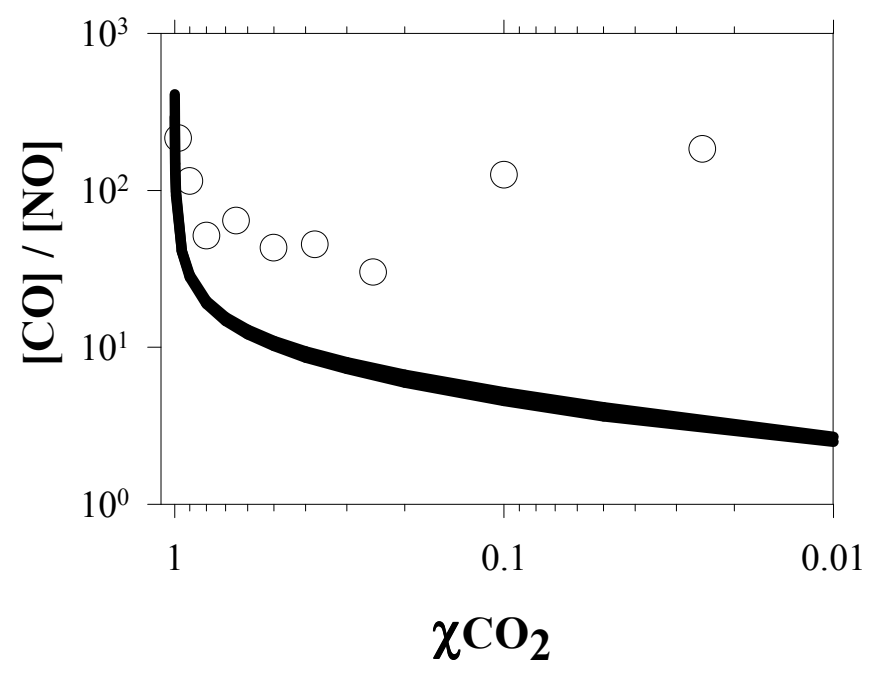

Figure 2

Ms. No. N11260B

Navarro-González et al. 